\title{
Razão instrumental como liberdade negativa? Sobre o leitmotiv da teoria crítica na obra de Axel Honneth
}

\author{
Instrumental Reason as Negative Freedom? On Critical Theory's \\ Leitmotiv in the Work of Axel Honneth
}

\author{
Mariana Teixeira \\ m.teixeira@fu-berlin.de \\ (Freie Universität Berlin, Berlim, Alemanha)
}

\begin{abstract}
Resumo: A hipertrofia da racionalidade instrumental na modernidade capitalista é uma das características marcantes da teoria crítica em termos de diagnóstico de tempo. Esse leitmotiv parece ser contradito ou, no melhor dos cenários, ofuscado na teoria do reconhecimento de Axel Honneth, representante da chamada terceira geração dessa tradição teórica. Neste artigo, traço um panorama dos posicionamentos de Honneth a esse respeito ao longo de sua obra, de Crítica do poder a Direito da liberdade, no intuito de mostrar que seu modelo teórico não só é compatível com, como fornece as bases para, uma crítica da razão instrumental como crítica da liberdade negativa - ainda que o próprio autor não tenha levado essa conexão até suas últimas consequências.
\end{abstract}

Palavras-chave: Axel Honneth; economia de mercado; razão instrumental; sociedade civil; liberdade negativa.

\begin{abstract}
The hypertrophy of instrumental rationality in capitalist modernity is one of the outstanding characteristics of critical theory in terms of time diagnosis. This leitmotiv seems to be contradicted or, at best, overshadowed in Axel Honneth's recognition theory, representative of the so-called third generation of this theoretical tradition. In this article, I give an overview of Honneth's stances in this regard throughout his work, from Critique of Power to Freedom's Right, in order to show that his theoretical model is not only compatible with, but also provides the basis for, a critique of instrumental reason as a critique of negative freedom even though the author himself has not taken this connection to its last consequences.
\end{abstract}

Keywords: Axel Honneth; market economy; instrumental reason; civil society; negative freedom.

\section{Introdução: ${ }^{1}$ razão instrumental e diagnóstico de tempo na teoria crítica}

A teoria crítica da Escola de Frankfurt é notória em seu diagnóstico do alastramento patológico da razão instrumental nas sociedades capitalistas. A partir

1 Desenvolvi parte dos argumentos que se seguem em minha tese de doutorado (Teixeira, 2016) e em um capítulo para o volume Axel Honneth and the Critical Theory of Recognition (Teixeira, 2019). A presente versão foi revista a partir das discussões que se seguiram à apresentação do texto no evento "The Critical Theory of Axel Honneth: Reconstruction, Capitalism, and Pathologies", realizado na Universidade de São Paulo em novembro de 2018. Gostaria de agradecer à organização e às/aos participantes do colóquio, assim como às/aos pareceristas que leram e comentaram o texto, mesmo que não tenha sido possível atender a todas as sugestões feitas. A pesquisa que deu origem a este artigo contou com o financiamento do Conselho Nacional de Desenvolvimento Científico e Tecnológico (CNPq). 
da combinação de temas marxistas e weberianos realizada por Georg Lukács em História e consciência de classe, a primeira e a segunda geração de teóricos críticos evidenciaram as consequências negativas da hipertrofia da racionalidade que acompanha a generalização da lógica anônima do mercado para virtualmente todos os aspectos da vida social. Pode-se mesmo argumentar que este é um leitmotiv da teoria crítica do século XX em termos de diagnóstico do tempo, já que é fundamental para a compreensão de diversas de suas categorias chave, desde a reificação de Georg Lukács, o homem unidimensional de Herbert Marcuse e o mundo administrado de Theodor Adorno até a colonização sistêmica do mundo da vida proposta por Jürgen Habermas.

Neste aspecto, Axel Honneth parece distanciar-se consideravelmente de seus antecessores na teoria crítica. A crítica da razão instrumental não exerce um papel significativo em Luta por reconhecimento (1992), sua obra mais conhecida; além disso, em Crítica do poder (1986), Honneth defende que os déficits teóricos dos modelos críticos anteriores se dão justamente pela insistência na ubiquidade da racionalidade instrumental e da integração sistêmica do mercado. 0 tema central da obra de Honneth é, em contraste, a infraestrutura normativa dos conflitos sociais - as motivações morais que subjazem até mesmo lutas por poder ou bens materiais. Somando-se a isso, como se pode observar em sua réplica a Nancy Fraser em Redistribuição ou reconhecimento? (2003), Honneth por vezes vai além de um questionamento da ênfase da teoria crítica na integração sistêmica e parece defender a tese de que não há integração sistêmica enquanto tal. Isso o levou a ser criticado por negligenciar todo um rol de patologias sociais engendradas pela internalização de imperativos de lucratividade do mercado em conexão com o controle técnico da sociedade e da natureza. Nesse sentido, Andrew Feenberg sugere em sua resenha de Crítica do poder que "a argumentação de Honneth falha em explicar o fato óbvio de que o controle da tecnologia serve de base ao poder em sociedades avançadas" (Feenberg, 1994, p.98). ${ }^{2}$

Pode-se contra-argumentar, porém, que o foco de Honneth na motivação moral das lutas sociais não exclui o diagnóstico de patologias sociais sistêmicas, geradas pela lógica calculadora e impessoal do mercado capitalista. Isso fica claro, por exemplo, em seus ensaios com viés marxista escritos na década de 1980, parcialmente reunidos em $O$ mundo dilacerado do social (1990), e também na recente transição do reconhecimento para a liberdade social como categoria fundamental da teoria honnethiana. Em Sofrimento de indeterminidade (2001) e Direito da liberdade (2011), pode-se identificar uma abertura teórica para a razão instrumental na forma de uma crítica da liberdade negativa - ainda que Honneth não leve essa abertura adiante

2 Trechos de obras que constam em língua estrangeira nas referências bibliográficas foram traduzidos pela autora. 
a ponto de estabelecer uma conexão entre a hipertrofia da liberdade negativa e a racionalização capitalista de atividades laborais.

Para defender esta interpretação, começo por reconstruir a crítica de Honneth ao diagnóstico habermasiano da colonização sistêmica do mundo da vida (1), para então apresentar sua abordagem alternativa a respeito da racionalização capitalista das atividades laborais (2). Essa abordagem, contudo, exerce um papel apenas marginal na teoria honnethiana do reconhecimento formulada subsequentemente, na qual não parece haver espaço para a razão instrumental ou a integração sistêmica - nem mesmo como manifestações de uma patologia social (3). Volto-me, então, para a obra recente de Honneth sobre liberdade social e argumento que sua crítica da liberdade negativa pode ser articulada a uma crítica da razão instrumental. Essa análise compreende dois argumentos: numa primeira tentativa, em Sofrimento de indeterminidade, Honneth recairia na "falácia da concretude deslocada" que havia criticado em Habermas (4), ao passo que em Direito da liberdade o autor mitigaria essa dificuldade (5). Na conclusão, esboço como a teoria da liberdade social poderia estabelecer uma conexão entre as patologias sociais da liberdade negativa e "os danos e destruições inerentes à modernização capitalista” (Honneth, 1999 [1986], p.23).

\section{A crítica a Habermas e à tese da colonização}

Na primeira parte de Crítica do poder, Honneth discute as dificuldades teóricas presentes nos textos de Horkheimer e Adorno, dando especial ênfase ao caráter monológico de uma antropologia filosófica apoiada no processo de dominação da natureza por meio da ação racional-instrumental e não na dimensão normativa de práticas intersubjetivas. Habermas aparece na terceira parte do livro, por outro lado, como o autor que traz precisamente as noções de intersubjetividade e normatividade para o palco central da teoria crítica, revertendo o monopólio de uma teoria social em que a ação humana é concebida ora como ação estratégica, ora como guiada por forças impessoais de controle. Decerto, Habermas não abandona o diagnóstico da primazia crescente da racionalidade instrumental voltada para a dominação da natureza e das pessoas, mas traz à luz uma concepção alternativa - comunicativa - de racionalidade, em nome da qual se poderia criticar o domínio da técnica. A unilateralização positivista da teoria científica, por exemplo, é criticada em vista da possibilidade de uma outra concepção de ciência, para além do campo da técnica e do controle. Assim, Habermas atribui a experiências comunicativas - e portanto a orientações de valor, àquilo que vai além dos limites do interesse próprio - uma eficácia motivacional ausente, ou presente apenas timidamente, nas formulações iniciais da teoria crítica. 
Honneth argumenta, entretanto, que em Conhecimento $e$ interesse (1968) Habermas sugere não um, mas dois modelos para o desenvolvimento histórico da espécie humana e que posteriormente, na Teoria da ação comunicativa (1981), ele teria optado pelo modelo mais próximo da teoria de sistemas, o que teria resultado em uma concepção reificada das dinâmicas de desenvolvimento social.

Em Conhecimento $e$ interesse, a divisão entre ação instrumental e ação comunicativa, ou entre trabalho e interação, podia ser interpretada de duas maneiras distintas. Por um lado, as dinâmicas conflituosas do desenvolvimento histórico podem ser vistas não só como presentes, mas mesmo como constitutivas da esfera comunicativa. Tais conflitos comunicativos afetariam, por sua vez, a conformação de relações sistêmicas ou instrumentais. Honneth aponta que há aqui uma possibilidade incipiente para se interpretar "a interação social também como luta de grupos sociais pela forma de organização da ação racional-instrumental" (Honneth, 1989 [1986], p.296, grifos no original). ${ }^{3}$ Esse embate não se dá meramente como competição estratégica entre diferentes atores sociais: o objeto do embate são normas institucionalizadas, de maneira que o conflito engloba a disputa comunicativa entre diferentes modelos interpretativos sobre a legitimidade das normas sociais. 0 embate entre grupos sociais é visto como um processo intersubjetivo que se inicia com a destruição das condições de reciprocidade da comunicação, se mantém na resistência de sujeitos lesados moralmente e termina, no melhor dos casos, com a renovação comunicativa de uma situação de reconhecimento mútuo. Essa concepção das dinâmicas intersubjetivas das lutas sociais implica, para Honneth, a inexistência de subsistemas sociais normativamente neutros, governados unicamente pela racionalidade instrumental: "as organizações aparentemente 'racional-instrumentais' são também codeterminadas por pontos de vista prático-morais que devem ser entendidos como resultado da ação comunicativa" (idem, p.303).

Este é, contudo, apenas um dos caminhos abertos pela teoria de Habermas - e que, para Honneth, não foi trilhado pelo autor. Outra possibilidade, que Habermas retoma e expande nos seus trabalhos subsequentes, implicaria conceber as dinâmicas conflituosas do desenvolvimento social como se dando não entre grupos sociais com diferentes posições na sociedade, mas, antes, entre esferas de ação. 0 conflito se daria, então, pelo fato de que a esfera comunicativa estaria sujeita à intervenção excessiva por parte do sistema - isto é, por relações econômicas e políticas mediadas não pela interação linguística, mas sim por dinheiro e poder. Daí surge, então, segundo Honneth, uma maneira mais rígida de se abordar o dualismo entre ação instrumental (voltada para a reprodução material da sociedade por meio do controle) e ação comunicativa (voltada para a reprodução cultural da sociedade por meio do

3 Traduzo o termo alemão zweckrational pela expressão "racional-instrumental" e Zweckrationalität por "racionalidade instrumental" ou "razão instrumental". 
entendimento).

A inclinação de Habermas para essa interpretação mais rígida da distinção entre sistema e mundo da vida apareceria, por exemplo, na concepção da economia capitalista e da estrutura administrativa estatal como dois subsistemas regulados não normativamente, mas sim apenas pela ação instrumental. Para Honneth, é problemático que essa suposta distinção analítica seja aplicada no domínio empírico dos fenômenos sociais: o dualismo entre sistema e mundo da vida não é apenas metodológico, como inicialmente proposto por Habermas mediante a distinção entre os pontos de vista do observador e do participante (idem, p. 324). Como consequência, os dois tipos de orientação da ação são reificados em esferas concretas de reprodução social como se houvesse, de fato, domínios sociais distinguíveis por serem ou não regulados de acordo com normas geradas comunicativamente - o que configura uma falácia da concretude deslocada (idem, p.282).

No entender de Honneth, são assim criadas duas ficções: uma esfera sistêmica neutralizada de normas morais e uma esfera comunicativa livre de conflitos, dominação e poder. Trata-se de ficções porque, por um lado, as estruturas organizacionais da administração econômica e estatal só podem ser compreendidas como formadas por uma combinação entre a lógica da ação estratégica e princípios normativos políticopráticos, que são produtos de um processo permanente de interação comunicativa. Como as regras da ação racional-instrumental são indeterminadas e sua aplicação social não pode se dar sem as regras da ação prática e política, esses princípios normativos formam as condições sob as quais fins administrativos são alcançados por meio da ação racional-instrumental (idem, pp.328-329). Honneth propõe, por outro lado, que o mundo da vida social não se reproduz independentemente da influência de práticas estratégicas e orientadas pelo cálculo, manifestas em várias formas de exercício de poder (idem, p.330).

Sem tomar isso em conta, diz Honneth, perdem-se de vista os processos cotidianos e pré-políticos do surgimento e da reprodução da dominação social. Além disso, na medida em que se enfatiza a colonização do mundo da vida pelo sistema como a patologia social central na modernidade, fenômenos problemáticos como a dominação de classe e as relações assimétricas de poder tendem a se diluir, posto que os conflitos são vistos como se dando entre diferentes esferas de ação e não entre grupos sociais diferentemente posicionados na estrutura de produção e reprodução do capital.

\section{A abordagem alternativa de Honneth: racionalização em disputa}

Durante a década de 1980, Honneth procurou desenvolver uma abordagem alternativa ao leitmotiv da teoria crítica - a crítica da razão instrumental nas 
sociedades capitalistas - com um viés marxista. Para ele, o marxismo só pode fazer jus ao seu potencial crítico, entretanto, se abandonar interpretações funcionalistas e reconstruir criticamente a categoria do trabalho (Honneth, 1980, pp.185-186). Para tanto, Honneth busca nos escritos do jovem Marx, em especial os Manuscritos econômico-filosóficos de 1844, as Teses sobre Feuerbach e A ideologia alemã, uma concepção dos processos laborais que não seja normativamente neutra e em que a produção não seja reduzida à racionalidade instrumental. Da mesma forma, conflitos sociais e econômicos não são vistos como postos em marcha por atores meramente maximizadores de utilidade: "Marx não concebe a luta de classes apenas como um embate estratégico visando a aquisição de bens ou poder de controle; ela representa, antes, um conflito moral em que a classe oprimida luta pelas condições sociais de seu autorrespeito" (Honneth, 1989, p.100). Seguindo Marx, Honneth argumenta que há um excedente emancipatório nas atividades laborais que se manifesta em processos de aprendizado não apenas cognitivo, mas também moral. Sem essa implicação normativa, de fato, não seria possível distinguir o trabalho livre do trabalho alienado. Portanto, o conceito de trabalho de Marx não é visto apenas como uma categoria descritiva, mas também prático-normativa, envolvendo desenvolvimentos técnicos e instrumentais bem como um "potencial formativo prático-moral que exerce um poder normativo de esclarecimento acerca das relações injustas do capitalismo" (Honneth, 1980, p.196). Esse processo prático-moral de aprendizado estaria então na base do potencial revolucionário do conceito de trabalho.

Em contraste, na visão de Honneth, as obras tardias de Marx implementaram uma mudança sutil, porém decisiva, no caráter pedagógico do trabalho:

em lugar de um modelo argumentativo que busca explicar a possibilidade da emancipação social diretamente a partir do potencial formativo [Bildungspotential] do trabalho, emergiu ali o modelo menos ambicioso em que a classe trabalhadora torna-se disciplinada e tecnicamente qualificada por meio do trabalho industrial na fábrica (idem, ibidem).

A ênfase recai agora sobre processos de aprendizado técnico e disciplinar no trabalho na fábrica, e não na experiência moral de indignação que surge das condições capitalistas de vida e de trabalho. Para Honneth, ao passo que os escritos do jovem Marx se apoiam majoritariamente em uma teoria da ação, sua obra tardia passa a focar numa análise sistêmica das crises enfrentadas pelas sociedades capitalistas (Honneth, 1989, pp.96-97). A conexão entre trabalho autônomo e emancipação - que sustentava a crítica do trabalho alienado na indústria capitalista - é abandonada em favor de uma visão mais determinista do potencial revolucionário inerente ao desenvolvimento tecnológico das forças produtivas. Como resultado,

as dimensões da problemática marxiana desaparecem de vista, posto que as condições de possibilidade de processos políticos de emancipação não são mais entendidas como 
se dando no nível das experiências sociais de sujeitos atuantes, mas sim projetadas no nível de processos sistêmicos autonomizados (Honneth, 1980, pp.197-198). ${ }^{4}$

Ao se descartar a função normativa do trabalho como conexão categorial entre uma crítica sistemática da economia política e uma teoria revolucionária orientada para a prática, instala-se uma crise na teoria marxista da revolução (idem, p.185). A categoria do trabalho, é, assim, normativamente neutralizada, e a tensão conceitual presente na obra de Marx entre trabalho alienado e não alienado reduz-se gradualmente em favor de uma interpretação ontológica do trabalho racionalizado que reflete apenas sua situação atual (e patológica):

As categorias do trabalho "alienado" ou "abstrato", com as quais Marx critica a organização capitalista da atividade laboral, praticamente desaparecem da linguagem teórica da filosofia social de orientação marxista, pois parece não haver um critério para formas de trabalho propriamente humanas, isto é, não alienadas, que seja independente de uma cultura particular (idem, p.214).

Decerto, para Honneth, o declínio conceitual do potencial emancipatório do trabalho no marxismo corresponde a uma neutralização normativa no nível histórico, com a racionalização e a fragmentação das atividades laborais advindas da taylorização do processo produtivo. Isto levou a uma separação sistemática entre o conhecimento teórico do trabalho e sua efetiva execução (idem, p.205) e, consequentemente, à separação entre, de um lado, poucos trabalhadores altamente qualificados em posições de controle e gerência e, de outro, um grande contingente de trabalhadores sem qualificação em posições subalternas e precárias (idem, pp.199-200). ${ }^{5}$ Mas esse diagnóstico não implica, para Honneth, a negação da dimensão normativa latente do trabalho. Uma concepção crítica de trabalho, pelo contrário, permite a distinção entre diferentes tipos de ação racional-instrumental de acordo com o grau de autonomia que os atores sociais têm ao exercê-las (idem, p.222).

A noção crítica de trabalho de Honneth busca evitar desse modo o confinamento, presente no dualismo habermasiano, das atividades laborais ao campo da ação racional-instrumental livre de normas. A lógica normativa interna do trabalho não corresponde, para Honneth, "nem à lógica de ações comunicativas, que visa à coordenação de intenções de ação orientada ao entendimento, nem à lógica das ações instrumentais, que visa ao domínio técnico dos processos naturais" (idem,

\footnotetext{
4 Honneth vê um processo semelhante na minimização do papel das lutas sociais na obra de Habermas: assim como, para Marx, a dialética entre forças produtivas e relações de produção substituiria a luta de classes como o "motor da história", para Habermas a oposição entre sistema e mundo de vida substituiria a disputa entre grupos sociais pela orientação normativa de complexos de ações racional-instrumentais.

5 Este processo contradiz empiricamente, portanto, também aquela esperança menos ambiciosa de que o aprendizado técnico pudesse contribuir para a organização da revolta dos trabalhadores contra o capitalismo, uma vez que não há uma correlação direta entre a intensificação da produtividade do trabalho e um aumento do nível de qualificação dos trabalhadores (idem, p.200).
} 
p.223), mas sim a uma combinação de ambas. Honneth identifica assim a existência de um conhecimento prático-moral que advém não da consciência da distorção sistemática das relações comunicativas, mas antes da experiência de expropriação das atividades produtivas de trabalho.

Importa destacar que o conhecimento moral latente nas atividades laborais pode se desvelar até mesmo no contexto de relações de trabalho amplamente racionalizadas e heterônomas por meio de diversas formas de resistência e reapropriação do controle dos processos produtivos por parte dos atores sociais. Honneth se apoia, aqui, em estudos que evidenciam estratégias cooperativas utilizadas pelos trabalhadores para resistir à expropriação de seu conhecimento prático e sua capacidade de iniciativa nas atividades laborais. ${ }^{6}$ Frente a essa expropriação sistemática, os trabalhadores reagem por meio de uma série de infrações e violações de normas com o objetivo de reaver (ainda que parcial e informalmente) o controle sobre as operações de produção. Tais estudos indicam que as políticas capitalistas de produção e "o trabalho industrial taylorizado e esvaziado de sentido" (Honneth, 1980, p.225) costumam vir acompanhados de uma força oposta mediante a qual os trabalhadores mobilizam cooperativamente um profundo conhecimento de suas atividades laborais como um meio informal de resistência prática no espaço de trabalho (Honneth, 1990 [1981], p.201). Mesmo o trabalho alienado ou expropriado contém, portanto, um "momento de rememoração prática" que pode trazer à superfície a percepção de que está em curso uma dominação injustificada (Honneth, 1980, p.225).

Segue-se disso que os trabalhadores expressam, em seus esforços para trazer os processos heterônomos de trabalho de volta ao horizonte das atividades exercidas de maneira autônoma, demandas que são imanentes às suas próprias atividades. Formas cotidianas de julgamento normativo subjacentes às práticas laborais são evidências de que a emancipação, no domínio do trabalho, não depende da referência a normas morais exógenas, e que conflitos de classe não ocorrem puramente devido à distribuição desigual de bens materiais: na base desses conflitos pode-se identificar a demanda por uma redefinição da dignidade humana e, portanto, por outra forma de reconhecimento social (Honneth, 1990 [1981], p.200).

Com sua noção criticamente reconstruída de trabalho, Honneth procurou assim distanciar-se das vertentes funcionalistas do marxismo que derivam a cultura de classe diretamente da posição de seus membros no processo de produção, o que teria o efeito de reforçar as estratégias de dominação que impedem que suas demandas alcancem visibilidade na arena pública. Cumpre notar que, mesmo que Honneth diagnostique uma erosão da normatividade do trabalho como resultado da sempre crescente demanda do sistema capitalista por cálculo e controle - o que leva à predominância da racionalidade instrumental sobre a ação intersubjetiva e

6 Cf. Bernoux (1979), Braverman (1998 [1974]) e Moore (1978). 
autônoma -, a ênfase do autor não recai nas patologias sociais que assim emergem, mas antes na perspectiva da resistência social que é inerente a tais patologias.

\section{Teoria do reconhecimento: qual o papel da crítica à razão instrumental?}

Em Luta por reconhecimento, Honneth expande seu foco da infraestrutura normativa da luta dos trabalhadores contra a mecanização das atividades laborais para englobar a gramática moral das lutas sociais em geral (Honneth 1994 [1992]). Ele considera que, enquanto as expectativas morais de indivíduos e grupos sociais transformam-se continuamente ao longo da história, a própria disposição para engajar-se em conflitos sociais buscando satisfazer essas expectativas pode ser considerada uma constante quase antropológica.

Honneth se opõe, dessa maneira, ao paradigma da filosofia política que toma unicamente os interesses individuais de autopreservação como a motivação dos sujeitos humanos. ${ }^{7}$ Tanto para Maquiavel quanto para Hobbes, por exemplo, discutidos no primeiro capítulo do livro, o objetivo da ação política é a estabilização do conflito permanente que surge da tendência "natural" dos indivíduos a buscar a satisfação de seus interesses por meio de relações estratégicas. Honneth abandona o paradigma das lutas por autopreservação por aquele das lutas por reconhecimento, de forma que a motivação dos conflitos deixa de ser o temor diante de ameaças à existência física: as lutas sociais são antes vistas como incitadas pela violação de expectativas de reconhecimento inscritas na estrutura das interações humanas. Tais atos de desrespeito surgem como violação do corpo (na esfera das relações afetivas primárias), negação de direitos iguais (na esfera das relações legais) e degradação (na esfera da estima social).

A ênfase que Honneth dá ao reconhecimento intersubjetivo como pré-condição para autorrealização não é uma novidade na sua trajetória, como pudemos observar em seus escritos sobre uma noção criticamente reconstruída de trabalho. No capítulo de Luta por reconhecimento dedicado às diferentes formas de desrespeito, contudo, a ausência de uma discussão sobre os impedimentos impostos aos atores sociais no âmbito do trabalho sob relações capitalistas contrasta com o diagnóstico anterior de Honneth da heteronomia patológica produzida por atividades laborais racionalizadas. De modo geral, pode-se dizer que a lógica da racionalidade instrumental não aparece no livro nem como uma dimensão legítima da ação humana nem como manifestação de uma patologia social.

\footnotetext{
7 Ao passo que a noção de indivíduo egoísta e autocentrado havia sido contestada por Honneth anteriormente com base em estudos sociológicos e historiográficos focados na dimensão normativa da luta de classes, ele agora se volta para Hegel e seus escritos de Jena - atualizados com recurso à abordagem de psicologia social de G. H. Mead - em busca de uma fundação filosófica contraposta à tendência de se reduzir a ação política à imposição racional-instrumental de poder.
} 
Diante da crítica de Nancy Fraser à ausência, na teoria do reconhecimento, de considerações substantivas acerca dos mecanismos de integração sistêmica e seus efeitos patológicos (Fraser 2003), Honneth afirma que não ignora a existência de imperativos econômicos e sua importância para a reprodução do capital, mas que sua intenção limitava-se a revelar as coerções morais subjacentes às interações sociais nas sociedades capitalistas (Honneth, 2003, p.249). A tese de Honneth é que a reprodução social se dá sempre sob a pressão normativa dos mecanismos de reconhecimento mútuo, concedendo portanto uma ampla primazia da integração social em relação à integração sistêmica: mesmo processos econômicos não poderiam ser considerados independentemente das expectativas normativas dos sujeitos envolvidos, posto que dependem ao menos de seu consentimento tácito, obtido por meio de negociações simbolicamente mediadas acerca da interpretação de princípios normativos (idem, pp.250-251). A legitimidade das instituições capitalistas, como o trabalho assalariado e as relações de mercado, dependeria assim do cumprimento ao menos parcial dos princípios da igualdade (como fonte de autorrespeito) e do mérito (como fonte de autoestima), ambos conquistados por meio de lutas sociais. Assim, por exemplo, a desregulação do mercado de trabalho é experimentada pelos atores sociais como perda de direitos, indicando que há, de fato, expectativas normativas no âmbito econômico. O princípio de maximização dos lucros não poderia, portanto, ser entendido como um requerimento funcional que dá ensejo, por si só, à esfera econômica como um domínio autônomo de ação social: ela

apenas se torna um tal "subsistema" de ação social quando encontra aceitação normativa suficiente para, com a ajuda de regulações jurídicas, formar uma instituição na qual uma complexa rede de ações individuais são coordenadas de modo aparentemente automático pela interação de considerações meramente utilitárias (idem, pp.255-256).

Mantém-se, ainda assim, uma ambivalência no posicionamento de Honneth que não pode ser ignorada: o que significa dizer que a coordenação de ações individuais pelas considerações utilitaristas é "aparentemente" automática? Há na teoria do reconhecimento, afinal, espaço para a integração sistêmica? Se considerarmos que esta depende de mecanismos autônomos, livres de valor, então a resposta deve ser negativa. Honneth admite, ao final de sua contribuição a Redistribuição ou reconhecimento?, que a oposição mesma entre integração social e sistêmica the parece problemática, posto que a reprodução das sociedades capitalistas sempre depende de um consenso moral mínimo capaz de satisfazer, ao menos parcialmente, as demandas normativas enraizadas nas interações sociais - já que mesmo o dinheiro ou o poder político dependem, para sua eficácia, da confiança em sua legitimidade por parte dos atores sociais, confiança que pode a qualquer momento enfraquecer ou mesmo entrar em colapso (idem, p.255). Dessa maneira, mesmo quando a perspectiva 
de maximização dos lucros parece ganhar primazia sobre quaisquer outros interesses e fins, Honneth ainda enxerga os processos econômicos como sendo permeados por um mínimo de considerações normativas. Como consequência, Honneth consolida aqui a tendência já presente em Luta por reconhecimento a desconsiderar - em lugar de complexificar - o papel das relações instrumentais nas sociedades de mercado contemporâneas.

\section{Liberdade negativa e indeterminidade: recaída na falácia da concretude deslocada}

Em Sofrimento de indeterminidade, de 2001, as patologias sociais analisadas por Honneth não dizem mais respeito à violação das diferentes dimensões das expectativas de reconhecimento, e sim ao exercício unilateral de concepções incompletas de liberdade. Seguindo a estrutura da Filosofia do direito de Hegel, Honneth identifica três modelos distintos de "vontade livre", em ordem crescente de complexidade: liberdade negativa, liberdade optativa e liberdade comunicativa, que correspondem, respectivamente, ao direito abstrato, à autonomia moral e à eticidade (Sittlichkeit) (cf. Tabela 1). As duas primeiras são formas necessárias de liberdade, ainda que deficientes: tanto o direito abstrato como a moralidade possuem um valor ético, um “direito de existência”, isto é, ambos têm um lugar adequado na realidade social (Honneth, 2007 [2001], p.73). A situação torna-se patológica, entretanto, quando esses modelos incompletos são tomados, sozinhos ou combinados um ao outro, como determinações suficientes da vontade livre. A indeterminidade constitutiva dessas formas parciais de liberdade passa assim a ser a única base para todas as ações e relações sociais, o que por sua vez torna-se uma fonte de sofrimento que se cristaliza em sentimentos de solidão, vacuidade e abatimento (idem, p.74).

(1.) 0 valor ético do direito abstrato reside em permitir aos sujeitos distanciarem-se das relações sociais concretas, uma indeterminidade que thes concede uma consciência de individualização legítima. As relações legais - apesar de constituírem uma instituição intersubjetiva, já que o estabelecimento de contratos indica o reconhecimento recíproco dos objetivos desejados pelos sujeitos (quaisquer que sejam) - representam, contudo, apenas o lado negativo da vontade individual: a remoção de toda limitação para a ação. A liberdade do outro aparece, nesse contexto, apenas como meio para a satisfação do interesse próprio. Caso todas as suas necessidades e intenções sejam articuladas pelas categorias limitadas do direito abstrato, o indivíduo torna-se incapaz de participar plenamente da vida social como um parceiro de relações éticas intersubjetivas, o que leva à primeira forma de patologia social como sofrimento de indeterminidade.

(2.) Enquanto no direito abstrato o objetivo da vontade livre é irrelevante para o conceito de liberdade individual, do ponto de vista da autonomia moral 
apenas as ações resultantes do processo de autodeterminação racional podem contar como ações livres. 0 valor ético da autonomia moral consiste, portanto, em permitir uma avaliação reflexiva dos argumentos racionais para se consentir em certa prática social. Seus limites residem, por sua vez, no fato de que esse exame reflexivo não pode ser indiferente ao contexto em que a normas de ação são colocadas em prática. Ainda que mais abrangente que o modelo negativo do direito abstrato, o modelo optativo de liberdade permanece insuficiente para assegurar as condições da autorrealização pessoal: ao insistir em um exame das normas que tem um caráter meramente introspectivo e transcendente ao contexto, a reflexão moral permanece vazia e eliminam-se todos os preceitos práticos que pautam a de capacidade de ação, o que conduz ao "tormento da vacuidade e da negatividade" (Hegel apud Honneth, 2007 [2001], p. 98).

(3.) Em contraste, a ideia de eticidade, domínio da liberdade comunicativa, é vista como tendo um sentido "terapêutico" na medida em que permite a autorrealização recíproca dos indivíduos em diferentes esferas relacionais. Com Hegel, Honneth vê na família, na sociedade civil e no Estado a possibilidade da liberdade como um "ser-consigo-mesmo-no-outro" (idem, p.62).

(3.a.) A família representa o primeiro modo de inclusão do indivíduo na eticidade pois "sem o reconhecimento intersubjetivo ao qual chegam as pulsões no espaço interior da família, a formação de uma 'segunda natureza', de um fundo socialmente partilhado em costumes e comportamentos, não seria possível” (idem, p.118). A família, assim, possibilita a socialização das necessidades humanas.

(3.b.) A sociedade civil, como esfera de interação entre sujeitos econômicos mediados pelo mercado, cria por sua vez uma ruptura com a natureza ética imediata da família e leva, ao quebrar os elos intersubjetivos entre os sujeitos enquanto membros da unidade familiar, a um "isolamento extremo" (idem, p.119). Ao mesmo tempo, a sociedade civil provê os meios para a realização de interesses individuais mediante a troca de bens e serviços. Em contraste com a família, nela o " "sistema de demandas' não se refere à esfera de comunicação orientada para as necessidades, mas ao controle sistêmico anônimo que permite o mercado satisfazer uma miríade de interesses" (idem, ibidem).

(3.c.) Em sua análise do Estado, por fim, Honneth contesta a interpretação de que Hegel seria indiferente à liberdade individual dos sujeitos enquanto cidadãos. Ele recorre às passagens da Filosofia do direito que indicam que no Estado os sujeitos adquirem um grau ainda maior de individualização, pois nele tornam suas habilidades particulares úteis ao interesse comum, participando ativamente na reprodução da coletividade por meio de uma "atividade universal" (idem, p.121). 0 sujeito tornase um membro da sociedade na esfera do Estado "não em sua carência natural, nem em seu interesse sempre individual, mas em seus talentos e habilidades formados 
racionalmente" (idem, pp.121-122).

A transição entre os graus crescentes de individualização, começando da família (a esfera das necessidades naturais), passando para a sociedade civil (a esfera dos interesses individuais) e chegando ao Estado (a esfera da reprodução coletiva via habilidades particulares) é caracterizada por Honneth como processo de formação (Bildung):

o sujeito chega ao nível máximo de individualidade quando, por meio da participação nas respectivas esferas, aprende a dispor gradualmente de esquemas cognitivos e argumentos que são construídos, um após o outro, no horizonte da "sensação", da racionalidade com respeito a fins [Zweckrationalität] e da razão [Vernunft] (idem, p.122).

É digno de nota, para os fins deste artigo, que o texto de Honneth sugere uma grande afinidade entre a liberdade negativa do direito abstrato (1.) e o domínio da sociedade civil (3.b.), já que neste "se encontram sujeitos individuais isolados com a finalidade de estabelecerem contratos mútuos sobre transações cujo cumprimento thes proporciona meios individuais para a realização de interesses que não são mais tão relevantes quando considerados reciprocamente" (idem, p.137). A sociedade civil é a esfera da satisfação, por meio da troca mediada pelo mercado de serviços e mercadorias, daqueles interesses e desejos privados dos sujeitos individuais que são formados sem levar em consideração as necessidades dos seus parceiros de interação (idem, ibidem). Assim como no direito abstrato, a reciprocidade exigida pelas relações de troca na sociedade civil só diz respeito, portanto, à consciência do caráter compulsório dos contratos e suas disposições específicas.

Hegel tinha ciência, como nota Honneth, do perigo de desintegração social trazido por esse aspecto do mercado capitalista. Essa intuição teria levado Hegel a incluir no escopo da sociedade civil um tipo de subsistema ético que poderia prover um grau maior de generalização social e bem comum: trata-se das corporações, nas quais "o sentido para o universal não é produzido pelo meio indireto da troca, mas pela via direta do estabelecimento de fins partilhados intersubjetivamente" (idem, p.139). Honneth sugere, entretanto, que faria mais sentido designar apenas o mercado à esfera da sociedade civil e lidar com as corporações na esfera do Estado, de modo a evitar o "constrangimento de ter que acomodar em uma mesma esfera duas formas de reconhecimento totalmente diferentes, das quais a primeira está ligada às transações mediadas pelo mercado, mas a segunda a interações orientadas por valores" (idem, p.142, grifos meus). Assim, contrariamente à sua insistência anterior na inserção normativa das relações de mercado, Honneth agora vê as trocas capitalistas como regidas pela lógica estratégica e anônima das ações autointeressadas, ao passo que as corporações são entendidas como forma diferenciada de uma liberdade pública, "que fornece aos sujeitos um sentido para a 
universalidade de suas atividades individuais" (idem, ibidem).

Desse modo, a concepção honnethiana de eticidade torna-se internamente diferenciada, englobando não apenas a liberdade comunicativa, mas também a liberdade negativa como um momento em seu processo de desenvolvimento. ${ }^{8}$ Essa abertura da eticidade para a ação estratégica visando objetivos individuais possibilita não apenas conceber um exercício legítimo da racionalidade instrumental, mas também criticar sua hipertrofia - que se dá quando o direito abstrato e sua forma negativa da liberdade ditam toda interação social entre os sujeitos. Honneth não chega, porém, a estabelecer uma conexão entre o sofrimento de indeterminidade gerado pela universalização da liberdade negativa e as patologias da economia de mercado. No livro, de fato, as patologias sociais estão delimitadas aos capítulos sobre o direito abstrato e a autonomia moral, ao passo que as três esferas da eticidade são caracterizadas apenas em seus aspectos positivos ou terapêuticos. Além disso, ao restringir a legitimidade da racionalidade instrumental à esfera do mercado, isto é, à sociedade civil, Honneth ecoa aqui a falácia da concretude deslocada que ele havia criticado no dualismo habermasiano entre sistema e mundo da vida.

Tabela 1 - Sofrimento de indeterminidade e Direito da liberdade

\begin{tabular}{|c|c|c|c|c|c|}
\hline \multirow[b]{2}{*}{$\begin{array}{c}\text { Sofrimento de } \\
\text { indeterminidade } \\
\text { (2001) }\end{array}$} & \multirow[b]{2}{*}{$\begin{array}{l}\text { 1. Direito } \\
\text { abstrato } \\
\text { liberdade } \\
\text { negativa }\end{array}$} & \multirow[b]{2}{*}{$\begin{array}{l}\text { 2. Moralidade } \\
\text { liberdade } \\
\text { optativa }\end{array}$} & \multicolumn{3}{|c|}{$\begin{array}{l}\text { 3. Eticidade } \\
\text { liberdade comunicativa }\end{array}$} \\
\hline & & & $\begin{array}{l}\text { 3.a. Família } \\
\text { sentimento }\end{array}$ & $\begin{array}{l}\text { 3.b. Sociedade } \\
\text { civil } \\
\text { racionalidade } \\
\text { instrumental }\end{array}$ & $\begin{array}{l}\text { 3.c. Estado } \\
\text { razão }\end{array}$ \\
\hline \multirow[b]{2}{*}{$\begin{array}{c}\text { Direito da } \\
\text { liberdade } \\
\text { (2011) }\end{array}$} & \multirow[b]{2}{*}{$\begin{array}{l}\text { 1. Liberdade } \\
\text { jurídica } \\
\text { liberdade } \\
\text { negativa }\end{array}$} & \multirow[b]{2}{*}{$\begin{array}{l}\text { 2. Liberdade } \\
\text { moral } \\
\text { liberdade } \\
\text { reflexiva }\end{array}$} & \multicolumn{3}{|c|}{$\begin{array}{l}\text { 3. Eticidade } \\
\text { liberdade social }\end{array}$} \\
\hline & & & $\begin{array}{l}\text { 3.a. Esfera } \\
\text { pessoal } \\
\text { amizade, } \\
\text { relações } \\
\text { íntimas, } \\
\text { famílias }\end{array}$ & $\begin{array}{l}\text { 3.b. Esfera } \\
\text { econômica } \\
\text { consumo, } \\
\text { produçãa } \\
\text { (mercado de } \\
\text { trabalho) }\end{array}$ & $\begin{array}{l}\text { 3.c. Esfera } \\
\text { política } \\
\text { esfera pública, } \\
\text { Estado } \\
\text { constitucional, } \\
\text { cultura política }\end{array}$ \\
\hline
\end{tabular}

8 Esse posicionamento teórico aparece também na crítica de Honneth à equiparação entre objetivação e reificação que teria sido empreendida por Lukács em seu clássico ensaio de 1923. Para Honneth, Lukács adotou uma postura tão totalizante que não foi capaz de "delimitar as esferas sociais em que o comportamento observador e indiferente possui um lugar perfeitamente legítimo" (Honneth, 2018 [2005], p.41), especialmente em sociedades altamente diferenciadas que, "por razões de eficácia", "exigem que seus membros aprendam a se relacionar de maneira estratégica consigo mesmos e com os outros" (idem, ibidem). 


\section{Crítica da razão instrumental como crítica da liberdade negativa}

Publicado dez anos depois, o livro Direito da liberdade exibe uma estrutura muito similar a Sofrimento de indeterminidade: as liberdades jurídica (1.) e moral (2.) são caracterizadas como formas necessárias mas não suficientes - e potencialmente patológicas - de liberdade, ao passo que a eticidade (3.) contém um significado emancipatório na medida em que corporifica, em seus diferentes complexos institucionais, o exercício de papéis complementares que permite aos indivíduos "serem-consigo-mesmos-no-outro". ${ }^{9}$ Contudo, se em Sofrimento de indeterminidade Honneth não se volta para os fenômenos problemáticos específicos da eticidade, ele o faz em Direito da liberdade mediante a noção de anomalias sociais (soziale Fehlentwicklungen).

As três esferas da eticidade - (3.a.) relações pessoais, (3.b.) ações econômicas de mercado e (3.c.) a formação da vontade democrática - são afetadas por anomalias sociais que, mesmo não tendo sido apresentadas de maneira sistemática por Honneth, podem ser em grande medida referidas à autonomização dos imperativos de lucratividade do mercado. Por essa razão, a caracterização da esfera econômica precede aqui a de seus efeitos negativos sobre a esfera pessoal e a política.

(3.b.) Na esfera econômica, Honneth sublinha dois alvos clássicos da Kapitalismuskritik: a exclusão social e o esgarçamento dos laços sociais. A crítica da exclusão social trata da promessa (não cumprida) do mercado de prover a cada um os meios de sua subsistência de acordo tanto com sua participação específica em atividades econômicas bem como com suas demandas particulares - isto é, o fracasso do mercado em alocar não só eficientemente mas também de maneira justa e solidária os recursos escassos em dada ordem social. Ainda que insista na inserção moral do mercado, Honneth não obstante admite que o sistema capitalista falhou retumbantemente em cumprir as expectativas que embasam sua legitimidade normativa, de maneira que seu desenvolvimento pode ser retratado como quase inteiramente anômalo, marcado pela pauperização social, a instabilidade dos empregos, a desvalorização dos salários e a escassez periódica de bens básicos causados pela orientação do mercado para a acumulação de capital. O consumo conspícuo de bens supérfluos marcando a distinção de status das elites reforça que é a lógica da lucratividade - e não a do reconhecimento mútuo entre sujeitos a respeito de suas demandas e contribuições - que prevalece na alocação capitalista de recursos.

\footnotetext{
9 Cf. Tabela 1. Pode-se observar que a terminologia de Honneth é sutilmente diferente. A moralidade é agora o domínio da liberdade reflexiva (em vez de optativa), e a eticidade corresponde à liberdade social (em vez de comunicativa), o que permite a Honneth localizar a teoria comunicativa de Habermas na tradição filosófica de origem kantiana e centrada na autonomia moral e não na liberdade social. Nas esferas da eticidade, por outro lado, Honneth se distancia do vocabulário hegeliano, deixando de lado os termos família, sociedade civil e Estado.
} 
A crítica do esgarçamento dos laços sociais, por sua vez, trata do fracasso do capitalismo em atender a promessa de que, no mercado, os indivíduos seriam capazes de reconhecer sua dependência mútua para satisfazer demandas materiais e de compreender suas próprias atividades como contribuições para a reprodução social. Ao descumprir essa promessa, a economia de mercado dissolve o reconhecimento dos papéis complementares que permitiriam que a liberdade do outro fosse enxergada como condição, e não entrave, à liberdade de cada um. Essa anomalia social se expressa de maneiras diversas. As expectativas sempre crescentes de eficiência levam, por um lado, a um aumento da mecanização e fragmentação dos processos de trabalho cujos efeitos são a depreciação das habilidades dos trabalhadores e a redução do valor social atribuído às atividades produtivas. A demanda pelo aumento da produtividade fomenta, por outro lado, um ambiente de trabalho enraizado em intensa competição, e não na cooperação entre os trabalhadores. Em tais ambientes, a atribuição individual do sucesso ou fracasso de cada projeto leva ao sentimento no trabalhador de ser o único responsável por sua sobrevivência no mercado, o que contribui, por sua vez, para a sua submissão a atividades degradantes e à instabilidade de emprego sem resistência coletiva. Além disso, a expectativa crescente por flexibilidade resulta na priorização de demandas do mercado em detrimento da manutenção de laços sociais autênticos e duradouros. Esse processo é reforçado pela internalização de padrões individualistas de comportamento baseados na cultura capitalista da soberania do consumidor, bem como pelo contínuo desenvolvimento da indústria cultural como meio de condicionamento de hábitos e preferências que assegura a demanda por bens produzidos em massa de maneira a evitar a ameaça da superprodução. Até mesmo no contexto do Estado de bem-estar social os trabalhadores são tratados como sujeitos jurídicos autocentrados, atomizados, e suas comunidades autonomamente reguladas tendem a perder força. Dessa forma, o indivíduo torna-se menos apto a enxergar a si mesmo como membro de uma classe autoconsciente, capaz de exercer alguma influência sobre a esfera produtiva, e a assimetria de poder entre os trabalhadores e a elite econômica, os empregadores e os donos dos meios de produção, atinge constantemente novos extremos. ${ }^{10}$

As consequências dessa erosão dos laços de solidariedade, contudo, vão além das fronteiras da esfera econômica: a autonomização gradual dos imperativos do mercado financeiro e do capital atinge também as esferas sociais vizinhas (Honneth, 2011, p.455).

10 Isto não significa que não haja qualquer resistência a esta anomalia social: existem formas de resistência não verbais, individualizadas e privadas, tais como a subversão ocasional das exigências do mercado consideradas excessivas ou irracionais. Em contraste com seus escritos anteriores, no entanto, Honneth enfatiza aqui a inadequação dessas tentativas de dar uma expressão política aos sentimentos de injustiça e desrespeito: sem fóruns e mecanismos discursivos apropriados para tematizar reflexivamente e negociar conjuntamente soluções para os problemas que os afetam, os indivíduos são privados da oportunidade de articular coletivamente a resistência. 
(3.a.) Como resultado da pressão sobre os indivíduos a submeterem o exercício de seus diversos papéis complementares ao imperativo de lucratividade do mercado, as relações pessoais deterioram-se. Em relações de amizade, por exemplo, a individualização dos sucessos e fracassos no mercado de trabalho e a necessidade de aumentar de forma constante a produtividade levam a uma significativa redução das ações livres de cálculo estratégico, essenciais para o florescimento de relações não interesseiras entre as pessoas.

Nas relações amorosas, diz Honneth, as pessoas estão cada vez menos dispostas a cultivar sentimentos de obrigação, aquiescência e autolimitação que são fundamentais para o exercício duradouro de papéis complementares no domínio do amor - um fenômeno atribuído em grande parte à prioridade que os atores sociais dão ao objetivo de autorrealização profissional em suas carreiras individuais. Consequentemente, as relações amorosas perdem espaço para - ou tornam-se perpassadas por - cálculos típicos do mercado de trabalho. Com a intensificação dos imperativos de flexibilização no trabalho e outras exigências que acompanham a "formação capitalista de subjetividade" (Dardot \& Laval, 2010), novos obstáculos se impõem à capacidade dos indivíduos envolvidos em uma relação amorosa de articularem autêntica e livremente suas identidades por meio da experimentação física e emocional de papéis normativos recíprocos.

Os imperativos do mercado têm consequências anômalas também no contexto da família. Aqui, contudo, não se trata da disseminação irrestrita da formação capitalista da subjetividade, e sim da deterioração das condições socioeconômicas vitais para o exercício não distorcido dos padrões normativos de ação característicos da vida familiar. Sob condições favoráveis, argumenta Honneth, os indivíduos deveriam ter garantidos o tempo e os meios necessários para exercer funções parentais, bem como uma perspectiva sólida no que diz respeito à subsistência material da família. A ausência de políticas sociais que garantam tais requisitos desencadeia uma anomalia social que impede o desenvolvimento de práticas normativas no contexto familiar. ${ }^{11}$ Honneth sublinha que, sendo a socialização das crianças uma das principais funções da família, o fracasso em cumprir tal papel resulta na diminuição da habilidade dos indivíduos de participarem ativamente no mundo social, econômico e político mais amplo.

(3.c.) Na esfera política, Honneth destaca a fragmentação da arena pública: a ausência de um horizonte cultural comum nas sociedades contemporâneas tem

11 Mesmo os sistemas de seguridade social dos países desenvolvidos são falhos, para Honneth, na medida em que os benefícios que concedem - como o auxílio em casos de doença, idade avançada ou desemprego - permanecem ligados ao exercício (atual, passado ou potencial) do trabalho remunerado. Já as atividades relacionadas à esfera da reprodução, ao cuidado dos membros mais vulneráveis da comunidade familiar (como crianças, idosos e pessoas com necessidades especiais), embora vitais para a realização da liberdade social no âmbito familiar, dificilmente recebem qualquer reconhecimento ou compensação social. 
consequências nocivas ao dificultar que se estabeleça um público democrático cujos participantes compartilhem um histórico comum e expectativas interconectadas de futuro. Uma fonte proeminente de tal anomalia é a exclusão política causada por desigualdades socioeconômicas. Honneth entende os Estados constitucionais modernos como marcados, desde sua origem, por uma seletividade de classe que favorece os interesses econômicos do estrato social mais alto - apesar do sistema político ter como propósito expresso representar a sociedade como um todo. Os próprios princípios normativos subjacentes à fundação do sistema político são assim sequestrados no exercício seletivo (e recorrentemente violento) do controle do Estado. Na medida em que parcelas da população são excluídas das tomadas de decisão políticas sobre matérias que as afetam, o aparato estatal torna-se impenetrável às suas demandas e necessidades e, como resultado, a sua relação com a esfera da política institucional é carregada de sentimentos de desconfiança. Tal percepção, porém, nem sempre toma forma em expressões coletivas de insatisfação, como protestos ou greves de cunho político. $\mathrm{O}$ desencanto com a política frequentemente leva à apatia e à indiferença, o que por sua vez conduz a uma maior deterioração dos mecanismos de participação democrática, formando-se então um ciclo vicioso entre exclusão e abstencionismo. A longevidade do consenso neoliberal torna cada vez mais claro que, apesar dos mecanismos democráticos, o sistema político segue privilegiando os interesses da elite econômica enquanto põe entraves para o exercício da autonomia legislativa de grandes parcelas da sociedade.

Esse panorama das anomalias da eticidade indica que Honneth atribui ao mercado e seus imperativos de lucratividade um papel central em Direito da liberdade. 0 fenômeno da formação capitalista da subjetividade surge como uma pressão dessocializante que afeta as relações sociais ao favorecer a satisfação dos sempre crescentes imperativos do mercado. Nas relações íntimas, os sujeitos são cada vez menos aptos a se comprometer a práticas recíprocas que, mesmo sendo essenciais para a manutenção de laços afetivos, possam causar quaisquer danos à empregabilidade conquistada por meio das diversas competências valorizadas pelo mercado de trabalho, como flexibilidade de horários, permanente disponibilidade para novas tarefas e a habilidade de estabelecer relacionamentos puramente estratégicos com os parceiros de interação. Na esfera da produção e do consumo mediados pelo mercado, apenas as liberdades contratuais aceitas legalmente estão garantidas, em detrimento da promessa do mercado de prover aos indivíduos segurança econômica, reconhecimento social e codeterminação. Na esfera política, por sua vez, solapase a possibilidade de um horizonte normativo comum e de mecanismos discursivos efetivos para a deliberação coletiva.

Observa-se, assim, uma transformação da correlação entre diferentes esferas da liberdade social. Idealmente, para Honneth, elas estariam vinculadas umas às 
outras em uma relação de "reciprocidade contributiva" (Honneth, 2011, p.615); seu diagnóstico de tempo, contudo, aponta precisamente para a ameaça de erosão interna na estrutura da liberdade social com a autonomização dos imperativos de lucratividade nas três esferas da eticidade. Com isso, tornam-se vitais medidas que favoreçam uma reinserção ética do mercado "que evite o surgimento do perigo de uma colonização das esferas vizinhas da liberdade social” (idem, p.276).

A necessidade de se estabelecer limitações normativas não implica, contudo, que o mercado seja constitutivamente desprovido de orientações de valor. Honneth insiste aqui - em contraste com o retrato da sociedade civil presente em Sofrimento de indeterminidade - que "as muitas restrições e regulações" que incidem sobre o mercado advêm "de sua base pré-contratual de legitimação" (idem, p.371).12 Assim, as anomalias sociais nas relações pessoais e na esfera pública política apenas podem ser descritas como uma colonização pelas relações de mercado se a própria esfera econômica for afetada por uma autonomização anômala dos imperativos de lucratividade em relação ao escopo moral no qual deveriam estar inseridos em uma situação não anômala. Dessa maneira, a penetração de outras esferas pelo mercado só pode ser considerada como uma anomalia social porque o próprio mercado é entendido como tendo se desenvolvido de maneira anômala.

É notável portanto que, em Direito da liberdade, Honneth mitiga a falácia da concretude deslocada presente em sua obra anterior, posto que a esfera econômica não é caracterizada como normativamente neutra, como é o caso da sociedade civil em Sofrimento de indeterminidade. ${ }^{13}$ Além disso, diferentemente do livro de 2001, em Direito da liberdade a própria eticidade é retratada não apenas em seu caráter terapêutico, mas também em seus aspectos problemáticos.

No entanto, Honneth negligencia também aqui o marcante paralelo entre a hipertrofia da liberdade negativa, com sua racionalidade meramente instrumental, e a força corrosiva da formação capitalista da subjetividade. Em vez de elaborar essa conexão, Honneth traça uma distinção conceitual mais ou menos rígida entre patologias, que surgem com a absolutização unilateral dos modelos jurídico e moral de liberdade, e anomalias, que afetam a liberdade social a partir de dentro. Tal distinção reproduz a desconexão presente em Sofrimento de indeterminidade: mais uma vez, as patologias sociais abordadas nos trechos sobre formas jurídicas e morais de liberdade desaparecem quando a eticidade entra em cena.

12 Elas devem ser destiladas a partir do seu embasamento moral (historicamente desmentido) por meio do que Honneth chama de reconstrução normativa, uma ferramenta metodológica que o autor apresenta na introdução de Direito da liberdade.

13 A inserção normativa do mercado em Direito da liberdade é clara na inclusão de Honneth das corporações nesta esfera - precisamente o que havia sido considerado em Sofrimento de indeterminidade um "constrangimento" para Hegel. 


\section{Considerações finais}

Temos, agora, uma imagem abrangente dos diferentes posicionamentos de Honneth com respeito ao leitmotiv da teoria crítica. Vimos que ele estabelece sua teoria do reconhecimento como uma abordagem alternativa à ênfase excessiva da teoria crítica precedente na onipresença da razão instrumental nas sociedades capitalistas avançadas, notando que a imagem do sistema econômico como uma esfera social normativamente neutra - tanto enquanto pressuposto ontológico como enquanto diagnóstico de tempo - leva a representações fictícias ou enganosas. Nessa linha, em vários ensaios escritos nos anos 1980, Honneth argumenta que análises empíricas sobre a racionalização e fragmentação das atividades laborais revelam uma disposição por parte dos trabalhadores em reivindicar o potencial normativo de suas práticas. Na formulação da teoria da luta por reconhecimento, bem como na defesa dessa teoria contra as críticas de Nancy Fraser, Honneth insiste na inserção moral no mercado. Demasiadamente na defensiva, contudo, ele acaba impossibilitando uma análise, a partir da teoria do reconhecimento, das patologias sociais daquilo que poderíamos chamar de "capitalismo realmente existente".

Em Sofrimento de indeterminidade, em contraste, a lógica do mercado é descrita como não regulada normativamente, corporificando, ao contrário, a busca pela realização dos interesses privados e autocentrados dos indivíduos por meio do exercício da racionalidade instrumental. A normatividade das interações econômicas é assim limitada ao reconhecimento mútuo dos indivíduos como capazes levar em conta a natureza vinculante da lei contratual, o que nos levou a questionar se Honneth reproduz aqui a falácia da concretude deslocada que criticara em Habermas: assim como no sistema habermasiano, a sociedade civil de Honneth aparece como livre de valores e normas em qualquer sentido substancial. Além disso, as esferas da eticidade parecem não ser afetadas pelas patologias sociais da liberdade individual e o sofrimento de indeterminidade resultante. Dessa maneira, ainda que Honneth leve em conta, agora, tanto um escopo legítimo para a ação estratégica quanto as consequências perniciosas de sua hipertrofia, sua abordagem se furta a identificar tais consequências na própria eticidade.

Parte dessas dificuldades é mitigada em Direito da liberdade, livro em que Honneth vê a racionalidade instrumental não como típica de um domínio de instituições específicas, mas sim como um modo da práxis social que permeia a eticidade. Diferentemente da sociedade civil, o mercado não é concebido como domínio da ação racional-instrumental per se. Além disso, Honneth agora está em condições - desde que se renuncie à distinção conceitual entre patologia e anomalia social - de conceber uma conexão promissora entre o recrudescimento da lógica racional-instrumental da liberdade negativa e a corrosão da liberdade social que 
afeta todas as esferas da eticidade nas sociedades capitalistas.

Por fim, há que se considerar que, ainda que agora ofereça uma interpretação a respeito da erosão da normatividade resultante da lógica racional-instrumental crescente nas relações sociais sob o capitalismo neoliberal, a abordagem recente de Honneth sobre a liberdade social tende a minimizar a perspectiva do participante no que diz respeito ao diagnóstico de (e resistência a) patologias sociais. Como exemplo, uma diferença marcante entre as noções de patologia social presentes em Sofrimento de indeterminidade e Direito da liberdade reside nas suas consequências para a experiência dos atores sociais: ainda que em ambos os casos as patologias sociais sejam concebidas como oriundas da hipertrofia das concepções jurídicas e morais de liberdade, no primeiro caso elas causam sentimentos negativos - vazio, solidão, descontentamento, insatisfação, abatimento -, ao passo que no segundo caso as consequências negativas das patologias sociais a partir da perspectiva dos participantes são deixadas quase completamente de lado. ${ }^{14}$ Precisamente essa perspectiva de baixo para cima permitira, contudo, que Honneth focasse, em seu posicionamento alternativo no tratamento da erosão normativa da práxis social, também na luta de classes, e não apenas em crises sistêmicas. 0 desafio para a teoria de Honneth hoje seria, assim, articular ambas as abordagens. A crítica da razão instrumental como crítica da liberdade negativa pode se beneficiar da sensibilidade da teoria do reconhecimento à gramática moral dos conflitos sociais, isto é, às experiências de injustiça que funcionam como força motivacional por trás da resistência social à reificação que tende a tudo abarcar.

\section{Referências}

Bernoux, P. (1979). La résistance ouvrière à la rationalisation: la réappropriation du travail. Sociologie du travail, 21(1), 76-90. DOI: https://doi.org/10.3406/sotra.1979.1599

Braverman, H. (1998 [1974]). Labor and Monopoly Capital: The Degradation of Work in the Twentieth Century. NY: Monthly Review Press.

Dardot, P.; Laval, C. (2010). Néolibéralisme et subjectivation capitaliste. Cités, 4, 35-50. DOI: http://doi.org/10.3917/cite.041.0035

Feenberg, A. (1994). The Technocracy Thesis Revisited: On The Critique of Power. Inquiry, 37, 85-102. DOI: https://doi.org/10.1080/00201749408602341

Fraser, N. (2003). "Social Justice in the Age of Identity Politics: Redistribution, Recognition, and Participation". In: Fraser, N.; Honneth, A. Redistribution or Recognition? A Political-Philosophical Exchange. Londres/NY: Verso, pp.7-109.

Honneth, A. (1980). „Arbeit und instrumentales Handeln. Kategoriale Probleme einer kritischen Gesellschaftstheorie“. In: Honneth, A. \& Jaeggi, U. (orgs.). Arbeit, Handlung, Normativität: Theorien des Historischen Materialismus, vol. 2. Frankfurt am Main: Suhrkamp, pp.185-233.

Honneth, A. (1989 [1986]). Kritik der Macht: Reflexionsstufen einer kritischen

14 Discuto esta diferença e suas implicações para a teoria crítica de Honneth em Teixeira (2017). 
Gesellschaftstheorie. Frankfurt am Main: Suhrkamp.

Honneth, A. (1990 [1981]). „Moralbewußtsein und soziale Klassenherrschaft. Einige Schwierigkeiten in der Analyse normativer Handlungspotentiale“. In: Die zerrissene Welt des Sozialen: Sozialphilosophische Aufsätze. Frankfurt am Main: Suhrkamp, pp.182-201.

Honneth, A. (1989). „Logik der Emanzipation. Zum philosophischen Erbe des Marxismus“. In: Krämer, H-L. \& Leggewie, C. (orgs.). Wege ins Reich der Freiheit. Berlin: Rotbuch, pp.86-106.

Honneth, A. (1994 [1992]). Kampf um Anerkennung: Zur moralischen Grammatik sozialer Konflikte. Mit einem neuen Nachwort. Frankfurt am Main: Suhrkamp.

Honneth, A. (1999 [1986]). „Eine Welt der Zerrissenheit. Zur untergründigen Aktualität von Lukács’ Frühwerk“. In: Die zerrissene Welt des Sozialen: Sozialphilosophische Aufsätze. Frankfurt am Main: Suhrkamp, pp.9-24.

Honneth, A. (2003). "The Point of Recognition: A Rejoinder to the Rejoinder". In: Fraser, N.; Honneth, A. Redistribution or Recognition? A Political-Philosophical Exchange. Trad. J. Ingram, C. Wilke. Londres/NY: Verso, pp.237-267.

Honneth, A. (2007 [2001]). Sofrimento de indeterminação: Uma reatualização da Filosofia do direito de Hegel. Trad. Rúrion Soares Melo. São Paulo: Singular; Esfera Pública.

Honneth, A. (2011). Das Recht der Freiheit: Grundriss einer demokratischen Sittlichkeit. Berlin: Suhrkamp.

Honneth, A. (2018 [2005]). Reificação: Um estudo de teoria do reconhecimento (edição ampliada). Trad. Rúrion Soares Melo. São Paulo: Editora Unesp.

Moore, B. (1978). Injustice: The Social Bases of Obedience and Revolt. Londres/ Basingstoke: Macmillan Press.

Teixeira, M. (2016). Patologias sociais, sofrimento e resistência: Reconstrução da negatividade latente na teoria crítica de Axel Honneth. Tese de Doutorado em Filosofia. Campinas: Instituto de Filosofia e Ciências Humanas, Universidade Estadual de Campinas.

Teixeira, M. (2017). "The Sociological Roots and Deficits of Axel Honneth's Theory of Recognition". In: Thompson, M. (org.). The Palgrave Handbook of Critical Theory. Londres: Palgrave Macmillan, pp.587-609. DOI: 10.1057/978-1-137-55801-5_27. DOI: http://doi.org/10.1057/978-1-137-55801-5_27

Teixeira, M. (2019). “Can Honneth's Theory Account for a Critique of Instrumental Reason? Capitalism and the Pathologies of Negative Freedom". In: Schmitz, V. (org.). Axel Honneth and the Critical Theory of Recognition. Londres: Palgrave Macmillan/Cham, pp.173-205. DOI: https://doi.org/10.1007/978-3-319-91980-5 8 